\title{
ALEJANDRA PIZARNIK: POESÍA, PROSA, HUMOR Y OTROS MISTERIOS*
}

\author{
AlEJANDRA PIZARNIK: POETRY, PROSE, \\ HUMOR AND OTHER MYSTERIES
}

\section{PAULINA DAZA D.*}

\section{RESUMEN}

En este artículo se proponen dos puntos estratégicos como claves para facilitar la entrada a la lectura de la Prosa de Humor de Alejandra Pizarnik. El primero, a través de la vinculación de las prosas de humor y la poesía publicada de la autora a partir de la idea de misterio. Y el segundo desde la revisión de los paratextos presentes en la prosa de humor.

Palabras clave: Alejandra Pizarnik, prosa, poesía, humor, misterio, paratextos.

\section{ABSTRACT}

In this article, two strategic cues are proposed to facilitate the reading of Alejandra Pizarni's Humorous Prose. The first one by establishing, through the idea of mystery, the link between the writer's humorous prose and her poetry published. And the second one by reviewing the paratexts that can be found in the humorous prose.

Keywords: Alejandra Pizarnik, prose, poetry, humor, mystery, paratexts.

Recibido: 21.11.11. Aceptado: 25.08.14.

* Este artículo corresponde a un capítulo de la tesis "Alejandra Pizarnik: Prosa de Humor. 'Reír de cosas no fijadas”, con la que la autora obtuvo el grado de Doctora en Literatura Latinoamericana en la Universidad de Concepción.

** Doctora en Literatura Latinoamericana. Pontificia Universidad Católica de Valparaíso. Valparaíso, Chile. Correo electrónico: daza.pau@gmail.com 
Nos anticipamos de sonrisa en sonrisa hasta la última esperanza.

Alejandra Pizarnik

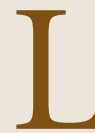
a lectura de la “Prosa de Humor” de Alejandra Pizarnik es una tarea difícil, puesto que la multiplicidad de sentidos en cada uno de los textos en ocasiones induce, por saturación, a creer que carecen de él. Este artículo se formula como una primera instancia en la que se proponen dos puntos estratégicos para facilitar la entrada a estos textos de humor.

En el primer punto se intenta encontrar a partir de la idea de misterio una vinculación entre poesía y humor en la obra de la escritora argentina.

En el segundo punto se hace una revisión de los paratextos presentes en la prosa de humor (índices, epígrafes, dedicatorias y "praefación”) con el fin de encontrar en ellos evidencias primarias de los temas, juegos intertextuales y lenguaje con los que el lector se encontrará en los textos de humor.

\section{POESÍA-HUMOR-PROSA}

Acceder a la lectura de los textos prosísticos de humor de Alejandra Pizarnik supone, en principio, dos opciones evidentes: recorrer el camino de su escritura desde su obra poética o desligar la escritura prosística de ataduras fundacionales y leer separando los textos de la poesía. Tomaré para el desarrollo de este artículo la primera opción intentando conectar ambas formas de escritura.

Para Pizarnik, el humor y la poesía están profundamente unidos, principalmente por el misterio que envuelve a ambos. La escritora señala: "Nada más misterioso e indefinible que el humor sino es la poesía, aunque debo decir que los identifico no poco" ("Humor"1). Aunque entre sus poemas, esencialmente trágicos, y su humor, aparentemente, sin sentido y obsceno parecen haber diferencias irreconciliables, es el misterio lo que la escritora intenta aprehender en ambos, un misterio que tiene estrecha relación con el lenguaje. En la poesía y el humor pizarnikianos nada es al azar, y ambas escrituras se presentan como una respuesta a una intensa angustia metafísica que la acompaña durante toda su vida y que la empuja a reflexionar en torno al lenguaje a través del mismo lenguaje. Cuando ella escoge y estudia obras de otros autores refleja veladamente la propia en el estudio de esa

\footnotetext{
1 "Humor". (Texto inédito). Pizarnik Papers, Archivo 7, carpeta 51. Biblioteca de la Universidad de Princeton.
} 
obra ajena ${ }^{2}$, lo que nos permite un encuentro en el que se pueden reconocer y explicar los procedimientos que utiliza o que desearía utilizar en su escritura. Por eso, es interesante su reflexión acerca de Historias de cronopios y famas en su artículo "Humor y poesía en un libro de Julio Cortázar Historias de cronopios y famas", cuando señala que, en general, el tipo de humor practicado por los autores contemporáneos "es un humor metafísico y casi siempre indiscernible de la poesía" (2003, p. 197). Es posible que en la obra de Pizarnik sus intenciones humorísticas siempre tengan un vínculo que las conecte a lo poético.

En la poesía pizarnikiana parece haber un "culto a la palabra", que se manifiesta en la búsqueda de la palabra "perfecta" , de manera que cada una debe instalarse con precisión y delicadeza en el poema para que este sea "puro". Por otra parte, en la prosa, la palabra parece acoplada a otras que funcionan como una "masa" que se moldea para originar formas procaces $^{4}$. De alguna manera la poesía es un cáliz contenedor donde el lenguaje es un líquido siempre en ebullición a punto de rebalsarlo. En la escritura en prosa, el leguaje desborda el cáliz y se libera, fluye salvaje y sin aparente control $^{5}$.

Cuando Pizarnik piensa la poesía y el humor como misteriosos e indescifrables $^{6}$, reflexiona sobre la imposibilidad de comprenderlos y expli-

\footnotetext{
${ }^{2}$ Ricardo Piglia señala en Crítica y ficción (2001): "En la polémica interna de las poéticas de los escritores se usan los escritores del pasado para no discutir personalmente" (pp. 158-159).

${ }^{3}$ Ivonne Bordelois indica en un testimonio citado por Cristina Piña en Alejandra Pizarnik. Una biografía: "Cada palabra era sopesada en sí misma y con respecto al poema como un diamante del cual una sola falla en diez mil facetas bastaría para hacer estallar el texto" (1999, p. 100).

${ }^{4}$ Los textos de humor de Pizarnik parecen de un género indefinible, por ello han sido catalogados en su prosa completa como "Prosa de humor". En su diario escribe en 1963: "Todo a medio hacer. Poemas en verso. Poemas en prosa. Cuentos de humor. Cuentos sin humor. Textos "automáticos"' (2003, p. 328). Esto nos indica que su intención primaria era escribir cuentos aunque finalmente haya decidido darles una forma y contenido ajeno al cuento tradicional.

En relación al cuento y la risa Luis Beltrán en su libro La imaginación literaria. La seriedad y la risa en la literatura occidental (2002), muestra una vinculación entre el cuento folclórico y el cuento literario (contemporáneo), señala: "El cuento es un género de naturaleza mixta: seriocómico. En su seriedad conecta la retórica, en su comicidad conecta con la tradición y el folclore. El cuento es un género esencialmente folclórico, que sólo tardíamente se incorpora al dominio literario. El cuento literario conserva deformada su naturaleza folclórica. (...) La risa es la principal manifestación de esta línea folclórica y durante mucho tiempo cuento y risa han sido dos conceptos en interdependencia" (p. 45).

${ }^{5}$ Sobre la escritura de humor en una carta dirigida a María Elena Arias López el 25 de junio de 1970 Pizarnik indica: "Y es difícil porque una -yo- (acaso nosotros) tiene prejuicios; no respeta el humor; cree (no lo cree pero en el fondo sí) que lo serio es más importante. En fin, me cuesta mucho exteriorizar mi humor que es velocísimo (y yo tan lenta)" (Bordelois, 1998, p. 113).

${ }^{6}$ Recordemos que también Roberto Juarroz se ha referido al misterio poético cuando señala en Diálogos con Guillermo Boido: "la poesía es el intento de expresar lo que casi es imposible expresar. Desde el punto de partida es, entonces, un misterio y una paradoja" (1980, p. 29).
} 
carlos de manera precisa. Pero todo aquello necesita de un lector capaz de dilucidar los acertijos y descifrar los enigmas aunque para ello hagan falta una serie de interpretaciones. Esa podría ser otra característica común de la poesía y el humor: la variedad de interpretaciones posibles dependiendo del lector, y del conocimiento y obsesiones que éste tenga. Los textos se convertirían en jeroglíficos que descifrar o sentencias misteriosas que necesitan una interpretación que cada lector le asignará según su cercanía con los temas, sus intereses personales e incluso desde su ignorancia. Otros intentarán descifrar y revelar el misterio para compartir el secreto con la escritora.

Entrar en contacto con el misterio que envuelve tanto la poesía como el humor de Pizarnik significa entrar en el reino de lo extraño, en el desconcierto que produce el uso del lenguaje, en la forma particular de utilizar las palabras para decir: el miedo, el silencio, la muerte, el dolor, la infancia, la risa, la burla, la alegría ${ }^{7}$. En la poesía de Alejandra Pizarnik la idea de que la palabra "dice lo que dice y además más y otra cosa" (2001a, p. 283) revela la ambigüedad abismante de cada palabra, de cada verso, de cada poema y de cada libro de la escritora. Aunque de alguna forma el misterio se resuelve en cada lectura, en la escritura permanece latente, extraño, ajeno, a la espera, porque el poema es ese lugar donde todo sucede. Pizarnik señala: "La poesía es el lugar donde todo sucede. A semejanza del amor, del humor, del suicidio, de todo acto profundamente subversivo, la poesía se desentiende de lo que no es su libertad o su verdad" (Piña, 1999, p. 107). En el poema y en el humor todo sucede ${ }^{8}$, todo lo que ella desea, por eso en su escritura, la poesía y el humor son actos subversivos que la escritora busca practicar durante la vida, hasta efectuar su último acto subversivo, el suicidio?.

Pizarnik leyendo y trabajando en sus poemas se convierte en una "ex-

${ }^{7}$ Cristina Piña señala en "Alejandra Pizarnik: una estética del deshecho" (1994): "Los libros de Alejandra publicados en vida están marcados, no sólo por un discurso poético que oscila entre el poema de extrema brevedad y poder de productividad significante y el poema en prosa extenso donde se va articulando una subjetividad que pone en constante juego su posición en el lenguaje, a través de la trasgresión semiótica del orden simbólico, sino por la plasmación de un sujeto textual marcado por el sello de la desolación y la tragedia: una endechadora -para darle uno de los tantos nombres que se le atribuyen a quien dice yo, tú o ella en el poema- encerrada en el laberinto de su soledad y cerrada a lo que no sea la exploración poética de los desgarramientos de su ser-en-el-lenguaje".

${ }^{8}$ Aunque en el poema la libertad está, aunque parezca paradojal, constreñida por el propio lenguaje poético. Allí, la libertad consiste en llevar al extremo la urgencia de decir la ausencia, la infancia, la muerte, la urgencia de nombrar libremente lo que antes era vacío. No se trata, entonces, de liberar el lenguaje a su autónoma voluntad sino a conjurarlo sabia y estratégicamente.

${ }^{9}$ Alejandra Pizarnik se suicidó consumiendo Seconal el 25 de septiembre de 1972, luego de dos intentos de suicidio que la mantuvieron entrando y saliendo del Hospital El Pirovano. 
ploradora" del lenguaje y del misterio. Este proceso le permitirá la creación poética a través de múltiples estrategias del lenguaje para llegar a "mostrar" lo que a veces le parece "innombrable". La autora señala en "Algunas claves de Alejandra Pizarnik"10: "Cuando algo -incluso la nada- tiene un nombre, parece menos hostil. Sin embargo, existe en mí una sospecha de que lo esencial es indecible" (2003, p. 313). Por otra parte, la extrañeza y la ambigüedad existe porque a pesar de desear nombrar, hacerlo también es un ritual misteriosamente peligroso. En el poema "Continuidad" escribe: "No nombrar las cosas por sus nombres. Las cosas tienen bordes dentados, vegetación lujuriosa" (2001, p. 235). La exploración del lenguaje significa también una indagación por caminos peligrosos que la seducen, por ese misterio con el que desea envolverse y cifrarlo en su obra, un misterio que la lleva a acercarse y poco a poco sumergirse en la locura, el silencio y la muerte, porque aquellos territorios fuera de los límites son los que desea recorrer, descifrar y reescribir. En su poesía se revela la presencia de la locura y el silencio, principalmente en sus últimos escritos ${ }^{11}$, pero antes del silencio viene la explosión del lenguaje, la locura misteriosa con que planeaba instantes de humor excéntrico, grotesco y aparentemente sin sentido.

Cuando hablamos de humor inevitablemente lo conectamos con la risa. Siguiendo a Pizarnik se puede señalar que tanto al humor como a la risa los rodea un misterio que hace imposible entenderlos y definirlos en su totalidad. En este sentido se hace necesario un acercamiento a la presencia de la risa. La vinculación de ésta con la obra poética publicada de la escritora es clara: no existe ${ }^{12}$, no hay espacio para ella o por lo menos no para la que se manifiesta en su "Prosa de Humor". En esta última la relación humor-risa, el uso de estrategias, el ingenio, la inteligencia en el humor de Pizarnik nos recuerda lo planteado por Henri Bergson en La risa: "En una sociedad de inteligencias puras quizás no se llorase, pero probablemente se reiría..." (2003, p. 13) y "lo cómico, para producir todo su efecto, exige como anestesia momentánea del corazón. Se dirige a la inteligencia pura" (p. 14). Pizarnik trabaja el humor como una actividad artística que se dirige

\footnotetext{
${ }^{10}$ Entrevista de Marta Isabel Moia, publicada en El deseo de la palabra, Ocnos, Barcelona, 1972. Recogida también en Prosa completa.

${ }^{11}$ Como he revisado en mi tesis de Magíster “'La poesía es un juego peligroso'. Vida poesía y locura en El infierno musical de Alejandra Pizarnik" (Daza, 2007).

${ }^{12}$ Con respecto al tema de la risa en la poesía de Pizarnik, Piña (1994) señala: "subjetividad así caracterizada está por igual apartada del contenido social y del cuerpo, y el tono de su indagación impide cualquier rasgo de humor que lleve a la risa o siquiera a la sonrisa".
} 
a esa "inteligencia pura" referida por Bergson, de la misma forma persigue la risa como actividad artística ${ }^{13}$.

En su prosa, siempre a través del lenguaje, la escritora ambiciona la instauración del humor para alcanzar la risa. Otro de los puntos en que convergen la poesía publicada y la prosa de humor pizarnikiana es en el intento de deshacer jerarquías, en la primera explorando el lenguaje para llegar a los límites de lo indecible y en la segunda siendo irreverente frente a todo, llenando el discurso de juegos lingüísticos y obscenidades sexuales.

Por otro lado, en los estudios realizados por críticos e investigadores como Cristina Piña y Patricia Venti, sobre la prosa humorística pizarnikinana, se reitera que la principal característica de ésta es su obscenidad. Cristina Piña señala en su artículo "Alejandra Pizarnik: una estética del deshecho" (1994): "La obscenidad de un lenguaje que se construye a partir de injertos/cortes/añadidos y remiendos que muestran sus costuras y su machihembraje". Aunque la aparición de la obscenidad sea una de las características que podría alejar los textos poéticos publicados de Pizarnik de su prosa de humor, ésta resulta ser uno de los puntos de unión entre ambas escrituras si recordamos que en la obra teatral "Los perturbados entre las lilas"14 el personaje Seg enuncia: "La obscenidad no existe. Existe la herida. El hombre presenta en sí mismo una herida que desgarra todo lo que en él vive, y que tal vez, o seguramente, le causó la misma vida" (2001b, p. 168). En el poema "En esta noche en este mundo" escribe: "Mi primera persona esta herida/ Mi primera persona del singular" (2001a, p. 398) y más tarde en una entrevista con Marta Isabel Moia señala:

Se ha dicho que el poeta es el gran terapeuta. En este sentido, el quehacer poético implicaría exorcizar, conjurar y, además, reparar. Escribir un poema para reparar la herida fundamental, la desgarradura. Porque todos estamos heridos (en Pizarnik, 2001b, p. 312).

\footnotetext{
${ }^{13}$ Arthur Koestler señala en El acto de creación ("Libro primero: el bufón"): "Hay un contraste obvio entre las reacciones emocionales del creador y del consumidor: la persona que inventa el chiste o la idea cómica raramente se ríe del proceso. La tensión creativa con la que trabaja no es del mismo tipo que la que se crea en la audiencia. El humorista está entregado a un ejercicio intelectual, a una acrobacia mental; aun cuando esté motivado por la inquina más acerba debe destilar y sublimar esta última. Una vez que da con la idea construye la estructura lógica, el patrón básico del chiste, usará los trucos del oficio, el suspense, el énfasis, la implicación, para modelar las emociones del público, para hacerle explotar en risas cuando el mecanismo sorpresa haga efecto en ellos" (2002, pp. 189-220).

${ }^{14}$ Obra teatral aparecida póstumamente bajo el nombre de "Los perturbados entre las lilas", en Textos de sombra y otros poemas (1982), y transformado luego en el poema "Los perturbados entre las lilas" aparecido, en El infierno musical, depurado del ruido de las múltiples voces del texto dramático y de su lenguaje grotesco.
} 
La poesía surge como una cura para la herida y luego la prosa de humor surge desde la herida, María Negroni señala en El testigo lúcido. La obra de sombra de Alejandra Pizarnik (2003): "Frente al deterioro de las palabras. Pizarnik renuncia al poema como instancia privilegiada de encuentro e intenta recuperar el sentido desde una gangrena" (p. 75). Una herida gangrenosa que se ha intentado, pero no se ha logrado curar. Poesía y prosa de humor fluyen impulsados por un mismo motivo: una herida que ha sido causada "por la misma vida" (Pizarnik, 2001a, p. 168). Esta idea nos conduce a lo siguiente: Poesía y prosa son literatura y para Pizarnik la literatura es la vida y viceversa. Encontramos por ejemplo en su Diario, en 1958, "Sí. He confundido literatura y vida" (2003, p. 107), y, en 1961: "La vida perdida para la literatura por culpa de la literatura. Quiero decir, por querer hacer de mi un personaje literario en la vida real fracaso en mi deseo de hacer literatura con mi vida real pues esta no existe: es literatura" (p. 200).

La literatura en tanto vida se manifiesta como un arma de doble filo, que al mismo tiempo cura y produce la herida. Quizás es por este motivo que el lenguaje de sus últimos textos poéticos tiende a colarse en las prosas de humor, recordemos poesía y prosa son paralelas. La poesía, siempre más controlada, depura el lenguaje y evita la aparición de una herida repulsiva, mientras que en la prosa el descontrol satura los textos y la poesía "púdica" intenta, ya sea como parodia o como una voz desesperada y trágica, recuperar su lugar, dialogando con un lenguaje insolente que intenta acallar la voz poética. Así encontramos por ejemplo en "Diversiones Púbicas":

Yo... mi muerte... la matadora que viene de la lejanía. ¿Y cuándo vendrá lo que esperamos? ¿Cuándo dejaremos de huir?

NO SEAS BOLUDA, SACHA (2003, p. 133) ${ }^{15}$

Entramos en la "Prosa de Humor" como quien salta a través de un espejo y nos encontramos en el reflejo especular del poema puro ${ }^{16}$ donde todo parece estar al revés y ser novedoso, donde nos envuelve un misterio, uno que a veces nos confunde, nos agrede y nos empuja a recorrer un camino que sorprende, pues tal como en la poesía todo puede suceder.

\footnotetext{
${ }^{15}$ En adelante sólo se citará el número de página de los textos en estudio.

${ }^{16}$ Susana Haydu señala en "Las dos voces de Alejandra Pizarnik" sobre la voz que surge de la prosa: "Esta otra voz, violenta y obscena, se vuelve obsesiva e incontrolable en los últimos escritos hasta oscurecer la voz poética presente en los textos anteriores" (1994). Desde la lectura que se realiza en este trabajo esa "otra voz" no oscurece sino que ilumina la poesía con el fin de mostrarse como su reflejo.
}

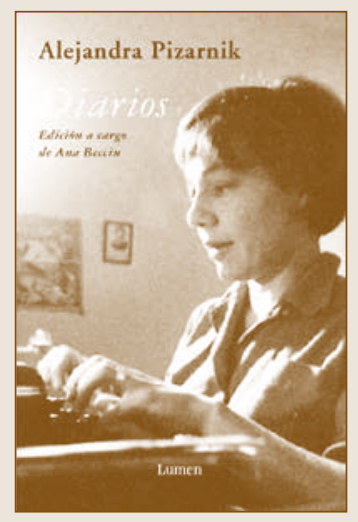




\section{UMBRALES QUE ANTICIPAN LA BURLA}

Puesto que en este apartado se intenta buscar o generar claves para facilitar el ingreso a la prosa de humor, se hace necesario comenzar por aquellos elementos que funcionan como dispositivos introductorios, por lo que revisaré los paratextos que incluye Pizarnik en su prosa. Estos se presentan al lector como pequeños enigmas que lo conducen hacia múltiples suposiciones (humorísticas o no) y/o confusiones que revelan desde el principio que la lectura no será fácil y que estará llena de mecanismos intertextuales y lingüísticos que se articulan en una mixtura inquietante y creativa. Me refiero a índices, dedicatorias, epígrafes y prefacios que resultan ser complementos humorísticos de cada texto y de todos los textos como conjunto.

\section{Índices}

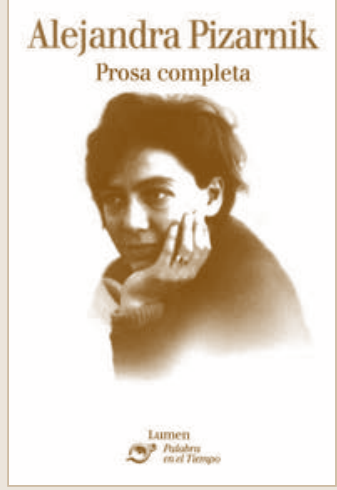

"La bucanera de Pernambuco o Hilda la polígrafa" es el título bajo el cual se reúnen casi todos los textos de humor ${ }^{17}$ publicados en la Prosa completa de Alejandra Pizarnik. Al iniciar este conjunto encontramos dos índices "tentativos" que se presentan como una parodia al índice clásico ${ }^{18}$. En primer lugar encontramos uno denominado "Índice ingenuo (o no)" dedicado "a las hijas de Loth" 19 y otro designado como "Índice Piola" dedicado a "la hija de Fanny Hill" 20 . Los personajes a quienes refieren estas dedicatorias son reconocidos, entre otras cosas, porque han transgredido las reglas morales a través de instancias sexuales perversas, por tanto, las dedicatorias son un primer guiño a lo que luego enfrentaremos en los textos, una escritura con la cual la escritora pretende transgredir el orden moral y lingüístico. Cada índice propone dos formas distintas de ordenación de los textos, ambos

\footnotetext{
${ }^{17}$ Fuera de este conjunto se encuentran "Historia del tío Jacinto y [Textos], debemos recordar que los escritos recogidos bajo el título 'Prosa de Humor' fueron publicados de manera póstuma, primero en 1982 en Textos de sombra y últimos poemas y luego el año 2002 en la Prosa completa editada por Lumen a cargo de Ana Becciu. Trabajo con esta última edición en la que los textos han sido organizados según el criterio de la editora.

${ }^{18}$ María Esperanza Gil señala sobre los epígrafes en su artículo "Poesía y humor: notas sobre la lectura de La Bucanera de Pernambuco o Hilda la Polígrafa"; "desde luego, ninguno cumple la función tradicional de índice porque no reproduce el orden de los textos, ni la cantidad, ni siquiera sus títulos correctos. (Disponible en http://www.ucm.es/info/especulo/numero39/hildapol.html Consultado en 2009).

${ }^{19}$ Las jóvenes que embriagaron a su padre para poder procrear y continuar su descendencia.

${ }^{20}$ La hija de Fanny Hill es la segunda parte de la novela Fanny Hill: Memoirs of a Woman of Pleasure, obra epistolar erótica-pornográfica, del inglés John Cleland.
} 
excluyen algunos textos e incluyen títulos inexistentes. En el caso del primer índice, cada texto está acompañado de una dedicatoria, y cada personaje al cual se refiere la dedicatoria tiene alguna relación con el humor, como el escritor Lichtenberg, y el actor Harpo Marx o con referencias hacia lo sexual ya sea que se trate de escritores de literatura erótica o pornográfica como Alexis Piron Ashbee, Saffo, Sader-Masoch o personajes reales o de ficción con conductas sexuales transgresoras como: Madame Warrens o la Marquesa d'O. Todo lo anterior indica que estamos ingresando en un terreno en el que lo humorístico y lo sexual irán de la mano. Cabe señalar que desde su adolescencia el sexo era una preocupación constante y turbulenta para la poeta y la deja ver con frecuencia en su escritura más íntima, la de su diario personal, en 1955 a los diecinueve años escribía por ejemplo:

Mi sexo gime. Lo mando al diablo. Insiste. Insiste. ¡Qué molesto es! ¡Cómo lo odio! Sexo. Todo cae ante él. Fumo para ver si se calma. Produce un alegre cosquilleo que recorre mi cuerpo. Dan deseos de tocarlo, de mirarlo, ver de dónde sale ese latir tan independiente de mi querer. ¡Es tan dueño de sí! Cruzo las piernas. Se calma un tanto. Sexo. El eterno sexo. Digo que lo odio, pero algo lo quiero ya que lo mimo tanto... (2003, p. 57).

La conjunción risa-sexo en su escritura no es al azar, pues ella misma la manifiesta con claridad en su Diario. En 1965, escribe, por ejemplo:

Algo totalmente opuesto al no, a la severidad, algo que se despliega como la risa o las ondas del orgasmo o un sendero de flores en un cuadro muy ingenuo. Como la boca llena de risa, como el sexo lleno de semen, como un sí afirmando sin cesar una danza ni lenta ni veloz, un moverse con infinita facilidad y docilidad. Ese idioma era el que yo soñé hace unos días y fui feliz pues creí que había puesto un nombre a mi extraño estar aquí, en este mundo anguloso, rectilíneo, cuyas aristas fueron corridas por el ácido del sueño (2003, p. 396).

La pugna contra el "no", contra la "severidad" que incluye y esconde: la seriedad, la insensibilidad, la intolerancia, el puritanismo y toda autoridad que exija una disciplina estricta, revela una rebeldía que pretende a toda costa quebrantar los límites impuestos a través de toda negación constante, de la expresión de un "no" impuesto por las reglas sociales, familiares, religiosas. Frente a ellas Pizarnik propone el humor y el sexo, "la risa" y "el orgasmo", como explosiones liberadoras que llenan la boca y el sexo de confianza y osadía. La escritura literaria a través de estos ámbitos desembo- 
ca en una muestra del "sí", como una liberación erótica feliz que Pizarnik expone a través de la insinuación erótica, el humor y la obscenidad.

\section{Dedicatorias}

Ocho de los veintiún textos agrupados en la "Prosa de humor" de Pizarnik cuentan con una dedicatoria: "Helioglobo -32-" dedicado a la escritora Silvina Ocampo; "La pájara en el ojo ajeno" al escritor Pietro Bacci-Baffo, Pietro Aretino Bacci y Giorgio Baffo, conocido por sus sonetos pornográficos $^{21}$ y al escritor español Antonio F. Molin; "La viuda del ciclista" a la condesa-escritora Felicité de Coiseul-Meuse (su apellido no es Coiseul sino Choiseul); "La Polka" al escritor Alexis Piron Ashbee; "La escrita" al escritor francés Nicolás Anne Edme Restif de la Bretonne; "Una musiquita muy cacoquímica" al personaje de los cuentos folclóricos clásicos alemanes Abate Calemberg y a la escritora argentina Martha Isabel Moia; "El textículo de la cuestión" a la Princesa Palatina ${ }^{22}$, y a la esposa de Italo Calvino Chichita Singer-Calvino, Esther Judit Singer, Chichita; y por último "La bucanera de Pernambuco o Hilda la polígrafa” a Gabrielle D’Estrées, amante del rey Enrique IV de Francia, y al escritor, periodista crítico literario Severo Sarduy ${ }^{23}$. Con respecto a la dedicatoria Gerard Gennete señala en Umbrales (2001):

... mencionar a una persona o una cosa como destinatario privilegiado, sin invocarlos de alguna manera, como antes el aedo invocaba la musa, y por tanto implicarlo como una suerte de inspirador ideal. "Para Un Tal" implica siempre un poco "Por Un Tal". El dedicatario es de alguna manera siempre responsable de la obra que le es dedicada y a la cual aporta volens nolens un poco de su participación (p. 117).

Lo cierto es que la sola mención de los personajes a quienes se remite en las dedicatorias sugiere que éstos, indudablemente, interesaron a Pizarnik. Cada dedicatario es un personaje público y cada uno remite principalmen-

${ }^{21}$ Pizarnik escribe en una de sus cartas a Ana María Barrenechea: "los impúdicos italianos (Aretino, Baffo y demás sinvergüenzas de esa época que decían malas palabras por doquier sin fijarse si había damas presentes)" (Bordelois, 1998, p. 100).

${ }^{22}$ Princesa francesa de costumbres licenciosas, reniega en un período de la religión y más tarde se reconvierte debido a un sueño.

${ }^{23}$ Pizarnik escribe acerca de Severo Sarduy en una de sus cartas a Ivonne Bordelois: "en Sarduy veo todo el tiempo un homosexual crispado por hacerse olvidar o perdonar -a través de otras cosas que al final resultan visajes o guiños- en fin, perdóname el diagnóstico tal vez apresurado, pero es de eso escritores con los cuales no puedo permanecer más de una carilla, y me encuentro en una suerte de malentendido visceral con él" (Bordelois, 1998, p. 266). 
te a la escritura de humor o a algún sujeto reconocido por haber llevado una vida libertina. Genette señala también que: "El dedicatario público es una persona más o menos conocida con quien el autor manifiesta tener, por su dedicatoria, una relación de orden público: intelectual, artístico, político u otros" (2001, p. 113). En el caso de las dedicatorias de Pizarnik la vinculación de los textos de la autora con estos personajes, su vida o su obra, manifiesta que los textos que se nos presentarán podrían tener estrechas relaciones con la literatura (metaliteratura), el humor y el sexo.

\section{Epígrafes}

En la "Prosa de humor" de Alejandra Pizarnik la relación entre los epígrafes y el texto es estrecha, cada epígrafe es un enunciado que por un lado complementa el texto en prosa y por otro se muestra como otra obra creada por la escritora a partir de lecturas o imágenes que en su particular forma de leer y aprovechar lo leído ha actualizado y reescrito, en algunos casos fielmente y en otros interviniendo los enunciados. Por otra parte, Alejandra Pizarnik juega atribuyéndole citas a diversos autores ${ }^{24}$. Podemos suponer que como lectora, sus múltiples lecturas han sufrido cortes a partir de los cuales la escritora ha generado nuevas escrituras.

La aparición de estos epígrafes puede producir dudas en el lector, relativas a la existencia real o ficticia del enunciado citado como epígrafe, es decir, caben las interrogantes $i E l$ epígrafe es real o ha sido creado por Pizarnik? ¿El epígrafe tiene relación con el desarrollo del texto o han sido colocados ahí solo por hacer referencia al tema ${ }^{25}$ ? ¿Si este epígrafe es una cita cuáles son sus referencias?

En esta primera revisión me ocuparé de los epígrafes como una creación complementaria pero, anexa a la obra en prosa. La presencia de los epígrafes se ha prestado incluso para errores de la crítica, pues se ha afirmado

${ }^{24}$ Gerard Genette señala acerca de los autores epigrafiados que: "El anonimato abarca situaciones muy diversas que la notoriedad pública o la erudición paciente puede eventualmente rastrear $\mathrm{o}$ asignar. El lector común cuando no tiene la ayuda de alguna nota editorial, permanece muy a menudo en una incertidumbre deseada por el epigrafista, librado a sus conjeturas" (2001, p. 130).

${ }^{25}$ Genette indica: "La pertinencia semántica del epígrafe es a menudo aleatoria, y podemos sospechar, sin la menor malevolencia, que ciertos autores ubican algunos a la buena de Dios, persuadidos de que toda relación hace sentido, y que aun la ausencia de sentido es un efecto de sentido, a menudo más estimulante, o más gratificante: pensar sin saber qué, ¿no es uno de los más puros placeres del espíritu?" (2001, p. 134). 


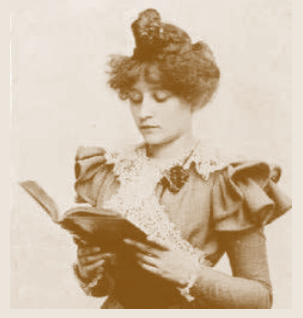

Colette constantemente que se trata de invenciones de Pizarnik, y aunque varias de las citas son apócrifas, no es así en todos los $\operatorname{casos}^{26}$. El siguiente es un breve recuento de algunos de los epígrafes presente en la prosa, con el fin de descubrir cuáles pueden ser los motivos de su inclusión, puesto que estos motivos nos servirán en el futuro como claves para entrar en la lectura de los textos de humor. Aunque intento demostrar que la aparición de estos epígrafes no es una simple invención ni han sido colocados arbitrariamente, debo aclarar que no en todos los casos se pueden obtener conexiones precisas entre epígrafe y texto de humor ${ }^{27}$, y lo que esta propuesta intenta es dibujar algunas líneas posibles desde donde ingresar en la lectura de los textos prosísticos.

A lo largo de la prosa encontramos diez epígrafes, de los cuales examinaremos cinco. En algunos casos importa la cita, en otros el autor $\operatorname{citado}^{28} y$ en otros casos la mixtura entre cita, autor y texto creado. El primero aparece en "[Textos]" en el apartado VI, "El erotómano" se trata de una auto-cita, la escritora toma del texto "Historia del tío Jacinto" una frase que por su insólita descripción de un parentesco (o no) resulta humorística: “¿Y qué hicieron mis abuelos la noche en que se acostaron juntos y descubrieron que ni él era mi abuelo ni ella mi abuela y viceversa?" (pp. 77 y 87). Este enunciado, a pesar de ser propio, está suscrito de la siguiente manera: $<<$ “COLETTE", “Claudel à l'école” >>. Efectivamente Sidonie Gabrielle Colette escritora, periodista y crítica francesa es la autora de una serie de novelas denominadas "las Claudines", y “Claudine à l'école" es la primera novela de la serie. La decisión de nombrar a esta autora y su novela bajo una cita atribuida puede leerse desde, por lo menos, tres posibilidades. Primero, Colette

\footnotetext{
${ }^{26}$ María Esperanza Gil en el artículo antes citado señala que "en los epígrafes puede observarse la heterogeneidad de un conjunto que incluye citas obviamente falsas y corrosivas ("Como a otros les duele el culo, a Grigori Efimovitch Novy le dolían las rosas”. Gregoria Malasuerte) junto a otras que están exentas de toda connotación humorística en su contexto original y en el del texto en que se insertan (“...buscando un hipopótamo”. L. Carroll) o, por último, la cita de Kafka (que la editora decidió ubicar al comienzo del libro) que admite una lectura humorística pero no la implica necesariamente. Al igual que en las dedicatorias, el diseño del sistema paratextual no admite una sola clave de lectura (la referencial, la humorística, la irónica) sino todas a la vez". (http://www.ucm.es/info/especulo/numero39/hildapol.html)

${ }^{27}$ Genette plantea que "La segunda función posible del epígrafe es sin duda la más canónica: consiste en un comentario del texto, que precisa o subraya indirectamente su significación. [...] Más a menudo es enigmático, con una significación que se aclarará o confirmará con la lectura del texto (2001, p. 135).

${ }^{28}$ Genette indica que "en un epígrafe lo esencial a menudo no es lo que dice, sino la identidad del autor y el efecto de garantía menos costosa, en general, que la de un prefacio y aun que la de una dedicatoria, ya que se puede obtener sin solicitar su autorización. También en un gran número de epígrafes lo importante es simplemente el nombre del autor citado (2001, p. 135).
} 
es, como otros personajes anteriormente nombrados, una figura femenina transgresora tanto en lo literario como en lo personal; la crítica señala que su obra reivindica los derechos de la carne sobre el espíritu y los de la mujer por sobre el hombre, lo cual escandalizaba a la sociedad parisina de principios del siglo XX, tanto como su separación de su primer marido y su participación como actriz en el music-hall. Segundo, la confusión familiar y de alguna manera genética que existe, se puede conectar con la novela mencionada de la escritora en la que una niña crece pensando que es un niño. Tercero, la inclusión de este epígrafe en el apartado VI "El erotómano", se puede pensar como una propuesta en la que desde el epígrafe se nos muestra la obscenidad de la obra y de la vida de una escritora, lo que más tarde en el texto epigrafiado se nos definirá de manera irónica como lo "inmundo".

Otro epígrafe aparece en el texto "Helioglobo -32-” del apartado II, "Algunos persopejes”, allí leemos “On ne s'apelle pas Bonichon, d' abord”. La inclusión de este epígrafe parece tener relación con el contenido del texto prosístico, en el cual se nos da a conocer los principales "persopejes" que distinguiremos en los siguientes textos del conjunto. Pizarnik aclara que los de su prosa no son personajes sino que son persopejes, por lo que podríamos parafrasear el epígrafe como "no se llaman personajes, en primer lugar..." (se llaman persopejes). La cita se atribuye a Alphonse Allais, un escritor francés de cuentos humorísticos, en los cuales todos los personajes sean buenos, asesinos o santos reciben el mismo trato, lo que hace sus narraciones singularmente divertidas. A partir de esta conexión deberíamos concluir que en las prosas de Pizarnik todos los personajes están en un mismo nivel, no hay buenos ni malos, lo cual bien manejado podría volver gracioso un texto.

El epígrafe que aparece en "Helioglobo -32-": "Buscando un hipopótamo" es interesante pues introduce concretamente una relación de la prosa de humor con el libro de Lewis Carroll Alicia a través del espejo, por ser este uno de los libros favoritos de Pizarnik ${ }^{29}$ podemos reconocer con certeza

\footnotetext{
${ }^{29}$ La crítica constantemente hace referencia a la cercanía del jardín de Alicia y la poesía pizarnikiana. La misma escritora lo hace cuando en entrevista con Marta Isabel Moia señala: "Una de las frases que más me obsesiona la dice la pequeña Alice en el país de las maravillas: - "Sólo vine a ver el jardín”. Para Alice y para mí, el jardín sería el lugar de la cita”(Pizarnik, 2001b, p. 311).

Así como en su poesía la constante aparición del jardín es un guiño hacia Alicia en el país de las maravillas y A través del espejo de Lewis Carroll, dentro de las prosas recogidas en Prosa completa existen varios textos que hacen referencias intertextuales explícitas a esta obra, hay uno en particular "El hombre del antifaz azul" en el que la autora reescribe con su particular ingenio una parte de Alicia en el país de las maravillas.
}

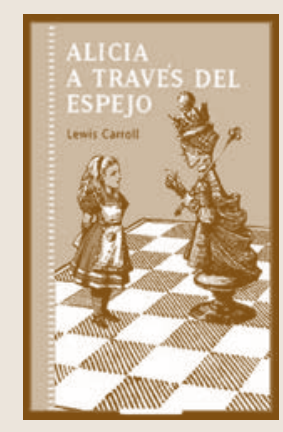


que hay gran influencia de él tanto en sus textos poéticos como en su prosa. Los personajes, los diálogos, las acciones y en general muchas escenas de la prosa de humor recuerdan los personajes conocidos y situaciones vividas por Alicia en el país de las maravillas y al otro lado del espejo. La aparición de este epígrafe en particular ayuda a estrechar la relación de la obra creada por Pizarnik con el autor y texto epigrafiados.

El texto "La polka" presenta dos epígrafes, ambos relativos a la polka, uno de ellos escrito en inglés y otro en francés. En una primera lectura vemos la polka como baile y un juego de palabras en el que "polkas" reemplaza a "portas".

\section{"Tom Plump gets married, and dances the Polka with his wife". "Adventures of Mr. Tom Plump" \\ "-Dis-moi comment tu polkes, je te dirai comment tu..." \\ Duncan Perros, La polka enseignée sans maître (p. 122).}

El epígrafe que aparece en inglés es la copia literal de un enunciado aparecido en el libro infantil de enseñanza de lectura inglés Six children's books of the 1850's. En el libro se ilustra una serie de imágenes en cuyo pie se explica la acción realizada por los personajes que se nos presentan. El protagonista es Mr. Tom Plump, un sujeto gordo que entre las actividades que realiza, como cita Pizarnik, se casa y baila polka.

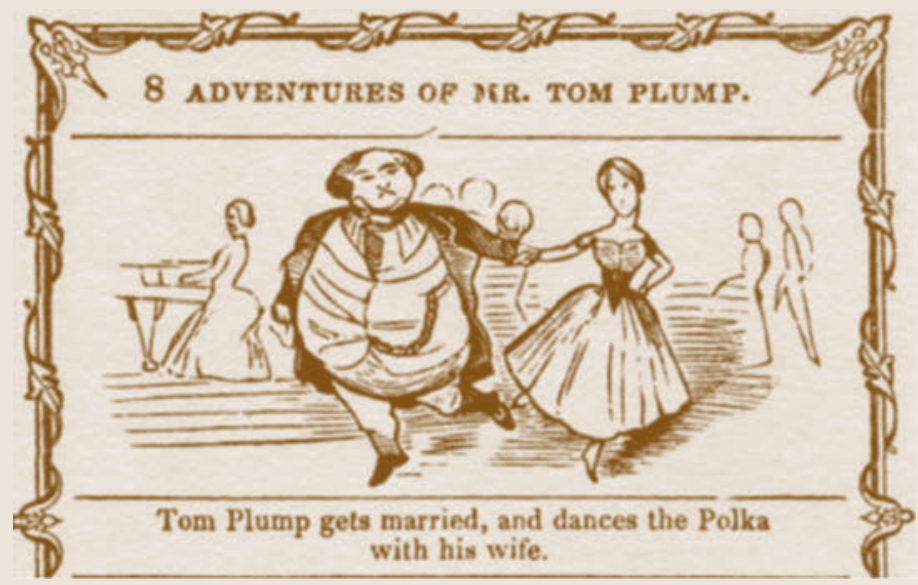


Puesto que el encuentro preciso de la cita epigrafiada permite la revisión del libro citado en su totalidad, se puede advertir que en él hay imágenes que, a pesar de tratarse de un libro infantil, son bastante inesperadas, trágicas y grotescas, como el fin de Mr. Tom Plump, quien por su enorme peso rompe un puente y cae a un río, lo cual produce una comicidad un tanto $\operatorname{siniestra}^{30}$.

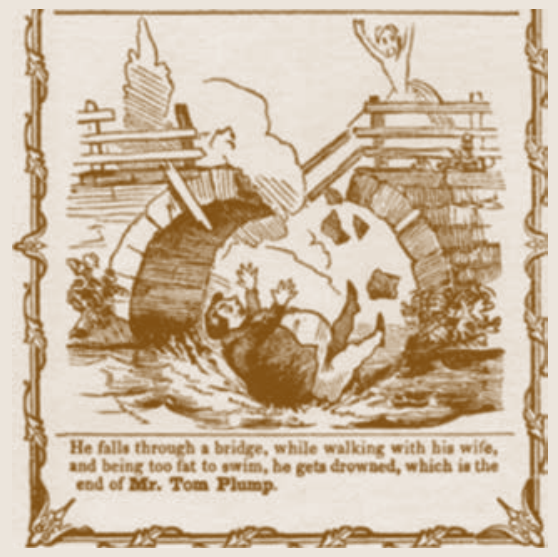

Por otra parte, algunas imágenes sugieren, cierta cercanía a Alicia en el país de las maravillas, se trata de animales tomando el té, tejiendo, tocando instrumentos musicales, mirándose al espejo y otra serie de personificaciones.
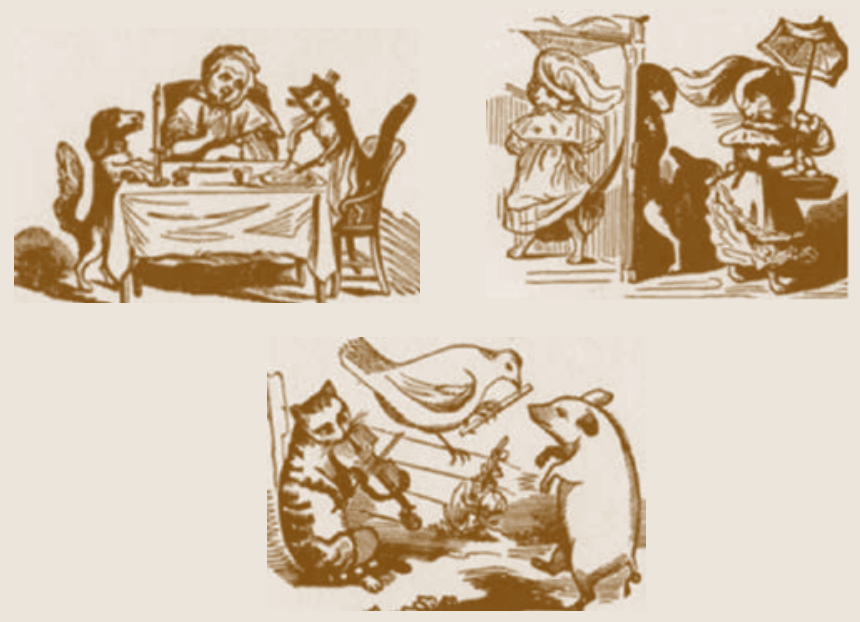

${ }^{30}$ Esto se relaciona con lo planteado por Cristina Piña en Alejandra Pizarnik. Una biografía acerca del humorismo cotidiano de la escritora: "ese humorismo insólito -y para algunos muy típicamente judío- se iría haciendo cada vez más obsceno y más sarcástico, cada vez más cruel..." (1999, p. 35). 
En el caso del segundo epígrafe se han encontrado referencias bibliográficas que prueban la existencia del libro La polka, enseignée sans maître y de éste se ha encontrado una nota a pie de página en la presentación del libro La danse des salons, de Cellarius, escrita por Remi Hess ${ }^{31}$. Aunque no se puede confirmar que el epígrafe utilizado por Pizarnik pertenece realmente a esta obra, se puede probar la existencia de tal libro y así sumarlo al amplio repertorio literario que ella aprovecha en la escritura de sus textos de humor.

\section{PRAEFACIÓN}

Dentro del conjunto de textos incluidos en "La bucanera de Pernambuco o Hilda la polígrafa" encontramos un texto denominado "Praefación" que cumple de manera paródica la función del tradicional Prefacio. En este, Pizarnik se dirige al lector con un discurso que parece incoherente y a veces violento. María Esperanza Gil (2008) se pregunta en su artículo "Poesía y humor: notas sobre la lectura de 'La bucanera de Pernambuco o Hilda la Polígrafa, de Alejandra Pizarnik”: “¿será Praefación una mezcla de prefacio y provocación?”. Este trabajo se inclina, más bien, por una mezcla entre "prefacio" e "imprecación"32 pues el texto más que cumplir con la función de un prefacio parece una imprecación, una suerte de reniego tanto de los textos como del lector que se presenta con total irreverencia. Sobre el prefacio tradicional recordemos que Gerard Genette (2001) señala:

El prefacio autoral asertivo original, que resumiremos como prefacio original, tiene por función cardinal la de asegurar al texto una buena

\footnotetext{
${ }^{31}$ Notamment par la publication d' un ouvrage de deux de ses élèves: Auguste Vitu et Paul Farnèse. Phicologie de la polke, d' après Cellarius (ilustration polkaïque), Paris, Ed. Gallois, in-32, 1844. Ce libvre en suscite un autre pour defender la methode d' E. Coralli, concurrent de Cellatius: Perrot et Robert, La polka enseignée sans maître, son origine, son developpement et son influenc dans le monde, d'après Eugène Coralli de l' Académie rouale (orné de ningt vigentes par Geoffroy), Paris, Auvert, 1845 (Hess, en Cellarius, 1987 [1847], p. 16).

32 Según la RAE “imprecación” corresponde a la "acción de imprecar” y a la "figura que consiste en imprecar". Por su parte "imprecar" para la Real Academia se define como "proferir palabras con que se expresa el vivo deseo de que alguien sufra mal o daño". En cuanto a la figura retórica, Marchese y Forradellas señalan que "imprecación" es una "figura lógica con la que se patentiza una fuerte emoción y por la cual se expresa desdén, indignación, furor por un acto negativo, y se desea mal a quien es responsable de ese hecho" (2007, p. 209).
} 
lectura. Esta fórmula simplista es más compleja de lo que puede parecer, puesto que se deja analizar en dos acciones, de las cuales la primera condiciona, sin garantizarla, la segunda, como una condición necesaria y no suficiente: 1. obtener una lectura, y 2. obtener que esta lectura sea buena (p. 168).

En "Praefación" las indicaciones para llegar a una buena lectura de los textos no es precisa y mucho menos es clara, más bien el lector puede sentir que la autora se burla de su futura lectura, pues no le da indicios ni claves y además deja en evidencia que no le importa su opinión final sobre los textos que se le ofrecen. María Esperanza Gil señala:

La convencional gratitud y la prescripción horaciana de agradar al lector quedan jocosamente de lado. Sin embargo, más allá del ácido humor con el que se establece el juego de la provocación (...), lo inquietante parece residir no ya en lo humorístico sino en la resonancia que produce la presencia de una segunda voz que, filtrándose a través de los paréntesis, murmura (-It’s O.K.), (Regio, Ché), (¡Es laloc!), (Seguí, no seas vos también la marquesa Caguetti.). Si aceptamos que laloc es La Locutora, personaje del texto, pero también la loca y si podemos leer la marquesa Caguetti como un mote irónico y a la vez una burla hacia alguien que tiene miedo (rasgo definitorio en la construcción del sujeto en la poética de Pizarnik), encontramos ya algunos motivos para creer que la inestabilidad del lector se debe al doble efecto de lo humorístico y lo extraño (2008).

Efectivamente se trata de un texto inquietante, pero más allá de lo humorístico y lo extraño queda al descubierto un trasfondo trágico que la escritora mezcla con una evidente agresividad. Como señala Gil, el prefacio podría leerse como una "provocación" o un reto hacia el lector, pues se inicia de la siguiente manera: "Me importa un carajo que aceptes el don de amor de un cuenticón llamado haschich: LA PÁJARA EN EL OJO AJENO" (p. 94) Y concluye así: "Lectoto o lecteta: mi desasimiento de tu aprobamierda te hará leerme a todo vapor" (p. 94).

Esto último parece el reto definitivo hacia el lector, pues se supone que el desinterés de la autora paradójicamente empujará al lector a leer los textos, aún sabiendo que su opinión no tendrá ningún valor. Pero si ponemos cuidado descubrimos que la escritora nos pone sobre aviso, nos da claves acerca de sus textos, orientando al lector, y además indica cómo se siente ella dentro de sus propios textos: 
Oculta tu voluntad antes que la voz del matante miedo ritme esta prosa por pendientes desfavorables. Voy a entrar en mi castillito de papel acompañada por un perro de niebla.

(...)

Pequeño ciervo mueve diminutos cierzos. Solamente yo emito señales vivas. Una bondad última ilumina las cosas.

(...)

¿Pero no resulta medio afligente ser la única náufraga sobreviviente en este cementerio hecho con aullidos de lobo... (p. 94).

La prosa de humor a la que nos introduce este Praefación es, como se ha señalado anteriormente, la escritura predilecta de Pizarnik en sus últimos años de vida, una escritura desesperada y poco esperanzadora que junto a sus libros de poemas La extracción de piedra de locura y El infierno musical son su última resistencia agónica a la locura y la muerte. Probablemente por este motivo la prosa es "un castillito de papel”, en oposición, además, al "castillo-torre de marfil" que en algún momento fue su propia poesía, en el que la única que emite señales de vida en medio del lenguaje que está muriendo es ella. Así podríamos comprender, también, por qué estas escrituras son "la última bondad que ilumina las cosas" (p. 94). Una figura semejante produce la voz que enuncia que es "la única náufraga sobreviviente en este cementerio hecho con aullidos de lobo" (p. 94). Ciertamente, leído así, este posible prefacio es un grito desesperado de la escritora que muestra su posición frente a sus creaciones prosísticas y poéticas, un grito de auxilio que se esconde bajo la agresividad con que se dirige al lector. Todo esto podría indicarnos que, como lectores, naufragaremos en una suerte de fauna pavorosa en la que Pizarnik intenta sobrevivir emitiendo aullidos en un castillo literario que más bien se ha convertido en un cementerio.

\section{REFERENCIAS}

Bataille, G. (2006). El erotismo. Buenos Aires: Tusquets.

Beltrán, L. (2002). La imaginación literaria. La seriedad y la risa en la literatura occidental. Barcelona: Montesinos.

Bergson, H. (2003 [1943]). La risa. Ensayo de la significación de lo cómico. Buenos Aires: Losada S.A.

Bordelois, I. (1998). Correspondencia Pizarnik. Buenos Aires: Seix Barral.

Cellarius, H. (1987 [1847]). La danse des salons. Texte présenté par Rémi Hess. Grenoble: Jerôme Millon. 
Daza, P. (2007). “La poesía es un juego peligroso’. Vida poesía y locura en $E l$ infierno musical de Alejandra Pizarnik". Tesis de Magíster en Literaturas Hispánicas, Universidad de Concepción. Dirigida por el profesor Mario Rodríguez $\mathrm{F}$.

Genette, G. (2001). Umbrales. México: Siglo Veintiuno.

Gil, M. E. (2008). "Poesía y humor: notas sobre la lectura de 'La bucanera de Pernambuco o Hilda la Polígrafa, de Alejandra Pizarnik". Espéculo. Revista de estudios literarios, 39. Universidad Complutense de Madrid. Disponible en: http://www.ucm.es/info/especulo/numero39/hildapol. html

Koestler, A. (2002). "El acto de creación. (Libro primero: el bufón)”. Cuadernos de Información y Comunicación, 7. Universidad Complutense de Madrid.

Haydu, S. (1994). "Las dos voces de Alejandra Pizarnik". En: Azar, I. (Ed.), El puente de las palabras: homenaje a David Lagmanovich (pp. 245-256). Washington: Organization of American States.

Juarroz, R. (1980). Poesía y creación. Diálogos con Guillermo Boido. Buenos Aires: Carlos Lohlé.

Moia, M. I. (1972). “Algunas claves de Alejandra Pizarnik”. En: Pizarnik, A., El deseo de la palabra. Barcelona: Ocnos.

Negroni, M. (2003). El testigo lúcido. La obra de sombra de Alejandra Pizarnik. Rosario: Beatriz Viterbo Editora.

Piglia, R. (2001). Crítica y ficción. Barcelona: Anagrama.

Piña, C. (1994). "Alejandra Pizarnik: una estética del deshecho". En: Azar, I. (Ed.), El puente de las palabras: homenaje a David Lagmanovich (pp. 330340). Washington: Organization of American States. . (1999). Alejandra Pizarnik. Una biografía. Buenos Aires: Corregidor.

Pizarnik, A. (2001a). Poesía completa (edición a cargo de Ana Becciu). Barcelona: Lumen. . (2001b). Prosa completa. Buenos Aires: Lumen. . (2003). Diarios (edición a cargo de Ana Becciu). Barcelona: Lumen. . "Humor". (Texto inédito). Pizarnik Papers, Archivo 7, carpeta 51. Biblioteca de la Universidad de Princeton.

VV.AA. (1960). Six children's books of the 1850's. Reprint. Scotia, New York: Americana Review.

Venti, P. (2003). "Las diversiones púbicas de Alejandra Pizarnik". Espéculo. Revista de estudios literarios, 23. Universidad Complutense de Madrid. Disponible en: https://pendientedemigracion.ucm.es/info/especulo/numero23/ pizarnik.html 